\title{
Vaccines, science and trust
}

To the Editor - Vaccines save lives. They are among the biggest successes in medicine and their safety and functionality are a widely shared consensus in science and society. This is made very clear in a recent Editorial on World Immunization Week $2017^{1}$. Most, if not all, readers of Nature Microbiology will agree. Yet dissident voices exist and some are dismissive of science or blatantly anti-science, or even resemble conspiracy theories. However, citizens that are critical of vaccination are often well informed and well read, and are aware of the potential of vaccines. Their critique, which may lead to a decision to not vaccinate (or to opt for fewer vaccinations), draws from an uneasiness of vaccination as a practice.

Citizens encounter vaccination practices most notably as new parents, where they observe that they are expected to behave in a certain way: namely to comply. Most of them do so and their babies get the shots. Some parents resist initially and some offer lasting resistance. However, as Geelen et al. show, compliance does not mean full agreement with the way vaccination practices are organized ${ }^{2}$. One might even expect that a large part of those who do comply may potentially resist the next time, or offer discrediting narratives to other prospective parents.
Dismissal of science is not what informs this uneasiness, as Geelen et al. show. Vaccination rates in the Netherlands, where they performed their study, are high. Parents are expected to vaccinate their child, and practices are designed accordingly. Doctors or nurses in the National Immunisation Programme announce the shot and give the shot. Parents' loyalty is assumed and they are disciplined to comply and offered almost no opportunity to ask (critical) questions or engage in conversations about vaccination. The scientific consensus that vaccines are safe and work is institutionalized into the vaccination practice to such an extent that every question mark is avoided and every critique is predetermined to be irrelevant. The result is a public who, while they may trust the safety and functionality of the vaccine, feels dismissed and ignored.

A vaccination office is not a laboratory. The scientific consensus on vaccination safety and functionality has a different meaning there. In order for scientific consensus to acquire public credibility and motivated loyalty through participation, it needs to be subject to public inquiry inquiry which may sometimes be critical. If the conversation is avoided, or unidirectional, it denies a voice to parents and citizens at large. Vaccination practices are about convincing and enabling people to enhance their and their child's future health - not the state enforcement of scientific consensus ${ }^{3}$.

Vaccines are safe and work. While the scientific credibility of that claim is irrevocable, the public credibility of the same claim requires a different type of work to maintain ${ }^{4}$. This work requires trust to be nurtured by allowing conversations between professionals and citizens - or as Geelen et al. phrase it: "experimenting with voice and exit" ${ }^{2}$. It requires a different role for scientific knowledge and expertise, humble instead of authoritative, inclusive instead of dismissive ${ }^{5}$.

References

1. Nat. Microbiol. 2, 17046 (2017)

2. Geelen, E., van Vliet, H., de Hoogh, P. \& Horstman, K. Soc. Sci. Med. 153, 12-19 (2016).

3. Hobson-West, P. Health Risk Soc. 5, 273-283 (2003).

4. Penders, B. Science 344, 693 (2014).

5. Jasanoff, S. Nature 450, 33 (2007).

Competing interests

The author declares no competing financial interests.

Bart Penders

Department of Health, Ethics \& Society, Care and Public Health Research Institute (CAPHRI), Maastricht University; PO Box 616, NL-6200 MD Maastricht, The Netherlands. e-mail:b.penders@maastrichtuniversity.nl 